Western University

Scholarship@Western

Aboriginal Policy Research Consortium International (APRCi)

3-6-2006

Injury profiles of Indigenous and non-Indigenous people in New South Wales

Kathleen F. Clapham

Mark R. Stevenson

Sing Kai Lo

Follow this and additional works at: https://ir.lib.uwo.ca/aprci

Part of the Other Public Health Commons

Citation of this paper:

Clapham, Kathleen F.; Stevenson, Mark R.; and Kai Lo, Sing, "Injury profiles of Indigenous and non-Indigenous people in New South Wales" (2006). Aboriginal Policy Research Consortium International (APRCi). 376.

https://ir.lib.uwo.ca/aprci/376 


\title{
Injury profiles of Indigenous and non-Indigenous people in New South Wales
}

\author{
Kathleen F Clapham, Mark R Stevenson and Sing Kai Lo
}

$T^{n}$ n Australia, injury is a leading cause of death, illness and disability, represent1 ing about $6 \%$ of all deaths and accounting for about $7 \%$ of hospital separations. ${ }^{1}$ In recognition of this burden, federal, state and territory governments have identified injury prevention as a health priority. ${ }^{2}$ The prevention of injury in, and promotion of safety to, Indigenous Australians is acknowledged as requiring particular attention. ${ }^{3}$ Hospitalisation rates for injury are one of the performance indicators for the National Strategic Framework for Aboriginal and Torres Strait Islander Health. ${ }^{4}$ It is difficult to make an accurate assessment of the extent to which Indigenous Australians experience injury, particularly in south-eastern Australia, where Indigenous status is substantially under-reported in hospital morbidity data. ${ }^{5-7}$ To date, there are few published studies describing the magnitude of injury among Indigenous Australians, and no study provides a comprehensive understanding of the impact of injury on their lives. Available evidence suggests that the overall burden of injury for Indigenous Australians is 2.8 times greater than for non-Indigenous people. ${ }^{8}$

There are about 119865 Indigenous people in New South Wales, comprising 27\% of the total Indigenous population of Australia. ${ }^{9}$ To date, the most reliable information on Indigenous injury in NSW comes from a small number of local area surveillance studies. ${ }^{10-}$ 12 These describe the context of injury and the effects of injury on individuals, communities and particular population subgroups. However, they do not describe the magnitude of difference in the rates of injury between Indigenous and non-Indigenous populations. Here, we report the incidence

\section{ABSTRACT}

Objectives: To compare the injury profiles of the Indigenous population in New South Wales with that of the non-Indigenous population.

Design and setting: Descriptive analysis of NSW Health data obtained from the Health Outcomes Information and Statistical Toolkit (HOIST) database. Hospitalisation data were collected for the period 1 July 1999 to 30 June 2003. Mortality data were collected for the period 1 January 1999 to 31 December 2002.

Main outcome measures: Hospitalisation and death rates due to injury by age, sex, injury mechanism and Indigenous status. Rate ratios for comparison between Indigenous and non-Indigenous populations.

Results: Rates of death from injury were higher for all age groups in the Indigenous population, except people older than 65 years. Indigenous people aged 25-44 years were twice as likely to be hospitalised as their non-Indigenous counterparts (rate ratio [RR], 2.09; 95\% Cl, 2.03-2.14), and five times as likely to be hospitalised for interpersonal violence (RR, 5.19; $95 \% \mathrm{Cl}$, 4.98-5.40).

Conclusion: The higher rates of injury-related hospitalisation and death in the Indigenous population in NSW are consistent with data reported for other parts of Australia. Of particular concern is the number of Indigenous deaths and hospitalisations due to interpersonal violence.

MJA 2006; 184: 217-220

of injury to Indigenous people compared with the non-Indigenous population in NSW over 4-year observational periods between 1999 and 2003.

\section{METHODS}

We used three data sources for our research: - De-identified injury hospitalisation data from the NSW Health Health Outcomes Information and Statistical Toolkit (HOIST) database for 1 July 1999 to 30 June 2003;

- De-identified injury mortality data from the HOIST database for 1 January 1999 to 31 December 2002; and

- Population data from the Australian Bureau of Statistics 2001 census of population and housing. ${ }^{9}$

HOIST is an electronic repository of health-related data collections which

Injury Prevention and Trauma Care Division, The George Institute for International Health, The University of Sydney, Sydney, NSW.

Kathleen F Clapham, PhD, Senior Research Fellow; Mark R Stevenson, PhD, Director.

Faculty of Health and Behavioural Sciences, Deakin University, Melbourne, VIC.

Sing Kai Lo, PhD, Associate Dean (Research) and Professor of Health Statistics.

Reprints will not be available from the authors. Correspondence: Dr Kathleen F Clapham,

Injury Prevention and Trauma Care Division, The George Institute for International Health,

The University of Sydney, Level 24, 207 Kent Street, Sydney, NSW 2000.

kclapham@thegeorgeinstitute.org includes datasets on deaths and hospitalisations throughout NSW. ${ }^{6}$ We did not use hospital emergency department data, as recent studies found regional and hospital variation in emergency information systems, and Indigenous status in emergency injury records in NSW less completely recorded than in hospital admissions data. ${ }^{10-12}$

We obtained data for all injury-related deaths and hospitalisations in NSW in 1999-2002 using International classification of disease (ICD-10) codes for injury (taken from Chapters 19 and 20). ${ }^{13}$ We calculated injury mortality and hospitalisation rates for Indigenous and non-Indigenous Australians for the same years using population data derived from the Australian Bureau of Statistics 2001 census of population and housing, in which NSW Indigenous profiles are available. ${ }^{9}$ Age-specific, sex-specific and injuryspecific mortality and hospitalisation rates were calculated. We calculated standardised mortality and morbidity rates by means of the direct standardisation approach using the NSW 2001 population as the standard.

In this article, we use the terms "Indigenous" and "Aboriginal and Torres Strait Islander" interchangeably. Ethical approval for the research was obtained from the 


\begin{tabular}{|c|c|c|c|c|c|}
\hline \multicolumn{6}{|c|}{$\begin{array}{l}1 \text { Injury-related deaths in New South Wales, } 1 \text { January } 1999 \text { to } 31 \text { December } \\
2002\end{array}$} \\
\hline \multirow[b]{2}{*}{ Parameter } & \multicolumn{2}{|c|}{ Indigenous } & \multicolumn{2}{|c|}{ Non-Indigenous } & \multirow[b]{2}{*}{ Rate ratio ${ }^{\dagger}(95 \% \mathrm{Cl}$} \\
\hline & Cases & Death rate* & Cases & Death rate* & \\
\hline \multicolumn{6}{|l|}{ Age group (years) } \\
\hline 0-14 & 32 & 16.73 & 316 & 6.61 & $2.53(1.76-3.64)$ \\
\hline $15-24$ & 39 & 46.33 & 1230 & 38.73 & $1.20(0.87-1.65)$ \\
\hline $25-44$ & 130 & 99.78 & 3119 & 43.70 & $2.28(1.92-2.72)$ \\
\hline $45-64$ & 38 & 63.62 & 1956 & 35.78 & $1.78(1.29-2.45)$ \\
\hline $65+$ & 13 & 97.48 & 3164 & 104.04 & $0.94(0.54-1.62)$ \\
\hline \multicolumn{6}{|l|}{ Sex } \\
\hline Male & 171 & 71.89 & 6780 & 58.09 & $1.24(1.06-1.44)$ \\
\hline Female & 81 & 33.62 & 3005 & 25.20 & $1.33(1.08-1.68)$ \\
\hline \multicolumn{6}{|l|}{ Injury mechanism } \\
\hline Falls & 8 & 1.67 & 904 & 3.83 & $0.44(0.22-0.88)$ \\
\hline Transport & 64 & 13.37 & 2327 & 9.86 & $1.36(1.06-1.74)$ \\
\hline Interpersonal violence & 33 & 6.89 & 371 & 1.57 & $4.39(3.07-6.27)$ \\
\hline Poisoning & 35 & 7.31 & 864 & 3.66 & $2.00(1.43-2.80)$ \\
\hline Self-harm & 65 & 13.58 & 2930 & 12.42 & $1.09(0.86-1.40)$ \\
\hline Other injuries & 47 & 9.82 & 2389 & 10.12 & $0.97(0.73-1.30)$ \\
\hline Total & 252 & 52.63 & 9785 & 41.47 & $1.27(1.12-1.44)$ \\
\hline
\end{tabular}

2 Injury-related hospitalisations in New South Wales, 1 July 1999 to 30 June 2003

\begin{tabular}{|c|c|c|c|c|c|}
\hline \multirow[b]{2}{*}{ Parameter } & \multicolumn{2}{|c|}{ Indigenous } & \multicolumn{2}{|c|}{ Non-Indigenous } & \multirow[b]{2}{*}{ Rate ratio ${ }^{\dagger}(95 \% \mathrm{Cl})$} \\
\hline & Cases & $\begin{array}{l}\text { Hospitalisa- } \\
\text { tion rate* }\end{array}$ & Cases & $\begin{array}{c}\text { Hospitalisa- } \\
\text { tion rate* }\end{array}$ & \\
\hline \multicolumn{6}{|l|}{ Age group (years) } \\
\hline $0-14$ & 3269 & 1709.08 & 86562 & 1812.01 & $0.94(0.91-0.98)$ \\
\hline $15-24$ & 2731 & 3244.39 & 82174 & 2587.25 & $1.25(1.21-1.30)$ \\
\hline $25-44$ & 5186 & 3980.29 & 136160 & 1907.87 & $2.09(2.03-2.14)$ \\
\hline $45-64$ & 1653 & 2767.55 & 98336 & 1798.96 & $1.54(1.47-1.61)$ \\
\hline $65+$ & 507 & 3801.74 & 150213 & 4939.16 & $0.77(0.71-0.84)$ \\
\hline \multicolumn{6}{|l|}{ Sex } \\
\hline Male & 7968 & 3349.64 & 317892 & 2723.46 & $1.23(1.21-1.27)$ \\
\hline Female & 5378 & 2232.20 & 235553 & 1975.26 & $1.13(1.10-1.16)$ \\
\hline \multicolumn{6}{|l|}{ Injury mechanism } \\
\hline Falls & 2839 & 592.94 & 176588 & 748.33 & $0.79(0.76-0.82)$ \\
\hline Transport & 1369 & 285.92 & 67254 & 285.00 & $1.00(0.95-1.06)$ \\
\hline Interpersonal violence & 2531 & 528.61 & 24053 & 101.93 & $5.19(4.98-5.40)$ \\
\hline Poisoning & 586 & 122.39 & 15166 & 64.27 & $1.90(1.75-2.07)$ \\
\hline Self-harm & 1080 & 225.56 & 28323 & 120.03 & $1.88(1.77-2.00)$ \\
\hline Other injuries & 4941 & 1031.95 & 242061 & 1025.79 & $1.01(0.98-1.04)$ \\
\hline Total & 13346 & 2787.36 & 553445 & 2345.35 & $1.19(1.17-1.21)$ \\
\hline
\end{tabular}

University of Sydney Human Research Ethics Committee.

\section{RESULTS}

\section{Deaths}

There were 252 Indigenous and 9785 nonIndigenous injury-related deaths in NSW between 1 January 1999 and 31 December 2002. Death rates for injury were higher for all age groups within the Indigenous population except those over 65 years (Box 1); the standardised mortality ratio for the NSW Indigenous population was 1.81 (95\% CI, 1.60-2.04).

The largest differentials between Indigenous and non-Indigenous injury-related deaths were in children aged 0-14 years and for adults aged 25-44 years. Death rates from injury for Indigenous males were more than twice that for Indigenous females, and $24 \%$ and $33 \%$ higher than for non-Indigenous males and females, respectively.

Self-harm and transport-related injuries accounted for over half of the injury-related deaths among Indigenous Australians in NSW (Box 1). Indigenous people were more than four times as likely to die as a result of injuries from interpersonal violence as nonIndigenous people, and twice as likely to die from poisoning.

\section{Injury}

There were 13346 Indigenous and 553445 non-Indigenous injury-related hospitalisations in NSW between 1 July 1999 and 30 June 2003 (Box 2). Hospitalisation rates for Indigenous injury were:

- higher for those aged 15-24 years, 2544 years and 45-64 years;

- lower for Indigenous people aged over 65 years; and

- similar to the non-Indigenous population for children 0-14 years.

The overall standardised morbidity ratio of 1.32 (95\% CI, 1.30-1.35) reflects excess injury-related morbidity among the Indigenous population compared with the NSW population.

The largest differential between Indigenous and non-Indigenous injury-related hospitalisations was for adults aged 25-44 years, who were more than twice as likely to be hospitalised as a result of injury than their non-Indigenous counterparts. Hospitalisation rates from injury for Indigenous males were $67 \%$ higher than for Indigenous females and $23 \%$ and $13 \%$ higher than nonIndigenous males and females, respectively. 


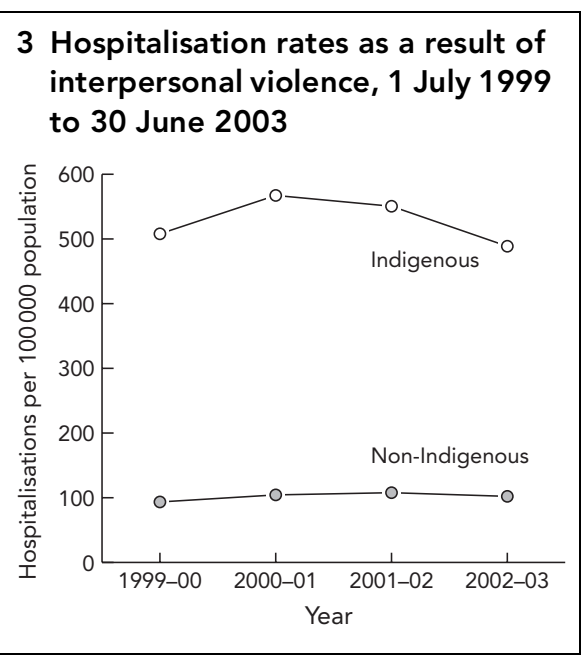

The greatest differences between the Indigenous and non-Indigenous populations were in hospitalisations resulting from intentional injury, with Indigenous people five times more likely to be hospitalised for interpersonal violence (Box 2). As shown in Box 3, the hospitalisation rate for interpersonal violence has remained relatively constant for both Indigenous and nonIndigenous populations over the 4-year observational period.

\section{DISCUSSION}

The high rate of injury in the Indigenous population compared with the non-Indigenous population in NSW is consistent with data recorded for the rest of Australia. ${ }^{8,14-16}$ Our findings show that an Indigenous person in NSW has a much greater risk of dying or being hospitalised as a result of injury than a non-Indigenous person. Of particular concern are the high rates of death among children aged 0-14 years and adults aged 25-44 years, and the significantly higher risks of death or hospitalisation for Indigenous people as a result of interpersonal violence and poisoning.

Injury problems in Indigenous communities are complex. They are interrelated with other health issues, and with socioeconomic and environmental conditions. ${ }^{8,14,15}$ There is growing awareness of the problem of violence in Indigenous communities, particularly widespread family violence. ${ }^{17-19}$ Factors underlying violence and self-harm have been identified as the effects of colonisation, loss of land, language and culture; the erosion of cultural and spiritual identity; racism and discrimination which undermine self-esteem and sense of personal wellbeing; the disintegration of family and community obligations that have traditionally sustained relationships and maintained social order and control; unresolved grief associated with multiple transgenerational trauma; loss of parenting and relationship skills; and lack of access to primary health care. ${ }^{14,20}$ Alcohol and substance misuse have also been identified as common contributing factors to injury. $^{15,21,22}$

Children aged 0-14 years are known to be particularly vulnerable to injury, ${ }^{2,21}$ but very little is known about the nature and extent of injury to Indigenous children. Injury issues which confront children in Indigenous communities are more complex than those commonly experienced within the general population, and are related to Indigenous social disadvantage, poverty and general ill health. Indigenous children may be put at risk through living in an overcrowded home environment, economic deprivation, high stress levels and recurring domestic violence. ${ }^{11-14}$ There is a lack of information about the extent of these problems across different geographical regions and about the relationship between substance misuse and child injury. Further, there is no age or sex breakdown of data, and too few studies within Indigenous communities in urban areas. ${ }^{23}$

Despite recent efforts to improve Indigenous identification in hospital data in $\mathrm{NSW}^{24}$ there are known limitations in Indigenous health data in this state. This is because of both substantial under-reporting of Indigenous status in data collections in NSW hospitals ${ }^{6}$ and reluctance by Indigenous people to report injuries. ${ }^{10-12}$ Serious injuries may be treated in emergency departments, or not treated at all. Fear of investigation or involvement with government departments, such as the Department of Community Services has also been cited as a reason for childhood injuries not being treated. ${ }^{11}$

Our findings are particularly relevant to primary care health practitioners and policy makers. Given the now growing body of literature highlighting the experience of violence in Indigenous communities in other parts of Australia, the findings in this report are very likely to be conservative. In considering the data, it is important to take into account the complex historical and social factors underlying Indigenous injury, as well as the much broader concept of what injury means to Indigenous people, encompassing not only the external causes but also the psychological and spiritual aspects.

Most injury is preventable, but Indigenous communities appear not to have bene- fited from pubic injury prevention strategies to the same extent as non-Indigenous people. ${ }^{21}$ There is a lack of interventions targeting injury prevention among Aboriginal and Torres Strait Islander people. ${ }^{14,15,21,25}$ Many Indigenous communities in NSW are working towards solutions for better health, safety and wellbeing, and promising examples of innovative and creative projects to address injury issues have been identified, ${ }^{25}$ However, the success of local initiatives is often impeded by lack of information to set priorities, inadequate skills within organisations and insecure funding. Indigenous injury prevention is a relatively new area of research, and there are few projects for preventing injury in urban areas where most Indigenous people live, and few that target young people, despite the Indigenous population being a "young" population. A new research study, Safe Koori Kids, aimed at building community interventions to improve the safety of urban Indigenous children and youth in NSW, will commence in $2006^{26}$

One of the principal failures of successive governments to improve Indigenous health is the failure to acknowledge the underlying social and economic causes of ill health and social disadvantage. There is an urgent need for government to recognise, support and strengthen the work already being done at the community level to address local priorities and to work together to develop more effective interventions. This can best be achieved by being prepared to work in a cross-sectoral context with a broad range of community and non-government partners, and by strengthening partnerships with Indigenous organisations, by assisting them to build capacity to tackle injury and safety issues in a culturally acceptable way.

\section{COMPETING INTERESTS}

None identified.

\section{REFERENCES}

1 Australian Institute of Health and Welfare. Australia's health 2004. Canberra: AlHW, 2004. (Catalogue No. AUS44.)

2 Strategic Injury Prevention Partnership. National injury prevention plan: priorities for 2001-2003. Canberra: Department of Health and Aged Care, 2001. (Catalogue No. 2918.)

3 NSW Department of Health. Aboriginal safety promotion strategy. Sydney: NSW Department of Health, 2003.

4 National Aboriginal and Torres Strait Islander Health Council. National strategic framework for Aboriginal and Torres Strait Islander health: framework for action by governments. Canberra: NATSIHC, 2003. 
5 Australian Bureau of Statistics and Australian Institute of Health and Welfare. The health and welfare of Australia's Aboriginal and Torres Strait Islander peoples. Canberra: ABS and AlHW, 2003.

6 Population Health Division. The health of the people of NSW: report of the Chief Health Officer, 2004. Sydney: NSW Department of Health, 2004: 112, 340.

7 Australian Bureau of Statistics and Australian Institute for Health and Welfare. Hospital statistics, Aboriginal and Torres Strait Islander Australians 1999-2000. ABS and AlHW, 2002. (ABS Catalogue No. 4711.0; AlHW Catalogue No. IHW 9.2002.)

8 Helps YLM, Harrison JE. Injury mortality of Aboriginal and Torres Strait Islander peoples in Australia 1997-2000. Canberra: Australian Institute of Health and Welfare, 2004.

9 Australian Bureau of Statistics. Census of population and housing. 2001 New South Wales (State 1) Indigenous profile. Canberra: ABS, 2002. (Catalogue No. 2002.0.)

$10 \mathrm{Mid}$ North Coast Aboriginal Health Partnership. Mid North Coast Aboriginal injury surveillance project report: pride, respect and responsibility. Port Macquarie: Mid North Coast Area Health Service, 2001.

11 Royal T, Westley-Wise V. Shoalhaven Aboriginal injury surveillance and prevention project: phase 1 report. Wollongong: Illawarra Area Health Service, 2001: 9-10.

12 Western Sydney Area Health Service. Blacktown Local Government Area injury surveillance and prevention study. United we win. Westmead: WSAHS, 2003: 12-13,30.

13 World Health Organization. International statistical classification of diseases and related health problems. 10th revision (ICD-10). Geneva: WHO, 1992

14 Harrison J, Miller E, Weeramanthri T, et al. Information sources for injury prevention among Indigenous Australians: status and prospects for improvements. Canberra: Australian Institute of Health and Welfare, 2001: 29.

15 Moller J, Thompson N, Brooks J. Injury prevention activity among Aboriginal and Torres Strait Islander peoples. Vol. 1. Current status and future directions. Canberra: Australian Government Department of Health and Ageing, 2004. (RFT129/0102.)

16 Stevenson M, Wallace L, Harrison J, et al. At risk in two worlds: injury mortality among Indigenous people in the US and Australia, 1990-92. Aust N Z J Public Health 1998; 22: 641-644.

17 Memmott P, Stacy R, Chambers C, Keys C. Violence in Indigenous communities: full report. Canberra: Crime Prevention Branch, Commonwealth Attorney-General's Department, 2001

18 Blagg H, Ray D, Murray R, Macarthy E. Crisis intervention in Aboriginal family violence: strategies and models for Western Australia. Perth: Crime Research Centre, University of Western Australia, 2000.

19 Gordon S, Hallahan K, Henry D. Putting the picture together. Inquiry into the response by government agencies to complaints of family violence and child abuse in Aboriginal communities. Perth: Department of Premier and Cabinet, 2002.

20 Bringing them home: national inquiry into the separation of Aboriginal and Torres Strait Islander children from their families. Sydney: Human Rights and Equal Opportunity Commission, 1997.
21 Pointer S, Harrison J, Bradley C. National injury prevention plan priorities for 2004 and beyond: a discussion paper. Injury Research and Statistics Series No. 18. Adelaide: Australian Institute of Health and Welfare, 2003. (AlHW Catalogue No. INJCAT 55.)

22 Australian Bureau of Statistics and Australian Institute of Health and Welfare. The health and welfare of Australia's Aboriginal and Torres Strait Islander peoples 2001. Canberra: ABS and AlHW, 2001

23 Stanley J, Tomison AM, Pocock J. Child abuse and neglect in Indigenous Australian communities. Child Abuse Prevention Issues Paper No. 19. Melbourne: Australian Institute of Family Studies, Spring 2003.

24 NSW Health Department. Better practice guidelines to improve the level of Aboriginal and Torres Strait Islander identification in the NSW Public Health System. Sydney: NSW Health Department, 2000. (State health Publication No. [CSP] 980163.)

25 Clapham K. Injury prevention activity among Aboriginal and Torres Strait Islander peoples. Vol. II. Programs, projects and actions. Australian Government Department of Health and Ageing, 2004. (RFT129/0102.)

26 Injury prevention for indigenous children is focus for new study. The George Institute for International Health. Sydney: The George Institute, 2005. Available at: http://www.thegeorgeinstitute.org/iih/media-and-publications/ latest-news/injury-prevention-for-indigenouschildren-is-focus-for-new-study.cfm (accessed Jan 2006).

(Received 16 Aug 2005, accepted 16 Jan 2006) 